\title{
An Economic Analysis of Sugarcane Farm Efficiency
}

\author{
Bhartendu Yadav*, Ram Singh Yadav², Vishakha Yadav', \\ Pavan Kumar Singh ${ }^{2}$ and Ajeet Kumar ${ }^{2}$ \\ ${ }^{1}$ CSAUA\&T-Nawabganj, Kanpur - 208002, India \\ ${ }^{2}$ ANDUA\&T- Kumarganj, Ayodhya - 224229, India \\ *Corresponding author
}

\section{A B S T R A C T}

\section{Keywords}

sugarcane, farm efficiency, production efficiency, PMWU, crop acreage

\section{Article Info}

\section{Accepted:}

10 January 2021

Available Online:

10 February 2021
India is the second largest sugarcane producers in the world, producing around 340-350 million tones of sugarcane per annum on 4.2 million ha area with a yield of $66.1 \mathrm{t} / \mathrm{ha}$. Uttar Pradesh being one of the largest sugarcane producer has Sant Kabeer Nagar district of Basti region has an optimum fraction in sugarcane generated economy. Therefore, the district was selected for the study. Ashrafpur, Debri, Malhepur, Vishunpura and Hakimpur villages were selected randomly from Haisar block. A total of 100 Sugarcane growers were selected randomly for this study. Efficiency of the land in terms of productivity was highest for marginal farmers i.e. 138.31 per cent, Productive man work units (PMWU) was calculated and found highest for medium farms i.e. 7523.71, and the Crop acreage per man was found highest for medium farmers i.e. $57.88 \mathrm{ha} / \mathrm{yr}$.

\section{Introduction}

An optimum fraction (nearly 60\%) of population still on agriculture directly or indirectly all over the world, "Statistical Yearbook", Food and Agriculture Organization, 2013. India is second largest producer of agricultural products. India accounts for 7.68 per cent of total global agricultural output. The importance and use of sugarcane and sugar in the country's socioeconomic milieu is deep rooted and immense.
In the current day rural economy set up on sugarcane cultivation and sugar industry has been focal point for socioeconomic development in the rural areas by mobilizing rural resources, generating employment and higher income, transport and communication facilities. Sugarcane is an important cash crop grown in India. India is the second largest sugarcane producers in the world, producing around 340-350 million tones of sugarcane per annum on 4.2 million ha area with a yield of $66.1 \mathrm{t} / \mathrm{ha}$. (Directorate of Economics and 
Statistics, DAC\&FW, 2015-16). About 7 million sugarcane farmers and large number of agricultural laborers are involved in sugarcane cultivation and ancillary activities. Apart from this, the sugar industry provides employment to 5 lakh skilled and semi-skilled workers in rural areas. In Indian economy agriculture shares nearly 17.9 per cent in GDP.

The average yield of cane stalk is $60-70$ tones per hectare per year. Sugarcane is the world's largest crop by production quantity, with 1.7 billion tones produced annually across 24 million ha worldwide, (The Food and Agriculture Organization, 2012). In spite of sufficient resources, technologies etc., a continuous and severe fall in production and land acquiring sugarcane cultivation can be seen in past years. It seems a genuine demand of time to study the economic aspects of sugarcane cultivation. The study on "an economic analysis of sugarcane farm efficiency" was undertaken with the objective to find out the various farm efficiencies on the sample farm.

\section{Materials and Methods}

\section{Selection of district}

Among the Basti division of eastern U.P., Sant Kabeer Nagar has a fertile land with good irrigation facility of gangetic plains. Moreover, the district is connected with transports very efficiently and has several sugar mills nearby. Therefore, the district was selected purposively.

\section{Selection of blocks}

A list of all nine blocks of the district was prepared along with their respective villages and thus, Haisar block was randomly chosen for the study of sugarcane crop keeping in view to avoid any operational inconvenience of the researcher.

\section{Sampling technique}

A list of all 225 villages of selected block was prepared separately along with their area under sugarcane cultivation and five villages namely Ashrafpur, Debri, Malhepur, Vishunpura and Hakimpur were selected randomly.

A separate list of sugarcane growers of selected villages was prepared along with their size of holding and further it was grouped into three categories i.e.

$\begin{array}{ll}\text { Marginal farmer } & \text { (below } 1 \mathrm{ha}) \\ \text { Small farmer } & \text { (1-2 ha), and } \\ \text { Medium farmer } & \text { (2-4ha \& above) }\end{array}$

Finally, 100 Sugarcane growers were selected randomly in proportion to their number of universe in each size group. Primary data was collected through personal interview with use of pre-structured and pre-tested schedule.

Secondary data was taken from the official records available at block, tehsil, and district offices. The data were collected for the agricultural year 2018-19.

\section{Farm efficiency}

Efficiency signifies a peak level performance the uses the least amount of inputs to achieve the highest amount of output. So, at a farm level efficiency means to achieve maximum productivity with minimum wasted effort or expense.

To make efficient decisions on farm broadly three efficiency measures are overlooked; Land, Labour \& Capital. Here Land and Labour are discussed as physical efficiency measures.

Measure of efficiency $=$ Output $/$ Input. 


\section{Land efficiency: Productivity of Land}

Production efficiency

$=\frac{\text { actual crop yield on the farm }}{\text { average yield in the locality }} \times 100$

Cropping Intensity

$=\frac{\text { Gross cropped area during the agricultural year }}{\text { Net cropped area }} \times 100$

\section{Labor efficiency}

PMWU per man equivalent

$=\frac{\text { total productive man work units }}{\text { man equivalent year }} \times 100$

Crop Acreage per Man Equivalent Year

$=\frac{\text { Number of acres under crop }}{\text { Man equivalent years }}$

Results and Discussion

\section{Farm efficiencies on sample farm}

\section{Land efficiency}

Land being a scarce resource must be used efficiently so that it can be generating optimum output rewards for the farmer (Table $1)$.

Hence, the details of the land production efficiency for sugarcane crop was studied, computed and are presented in the (Table 2).

The (Table 2) infers that the cropping intensity was found highest for marginal farmers, 203.03 per cent followed by small and medium farmers, 195.20 per cent and 181.78 per cent.

It reveals that the optimum use of land was efficiently done and performed by the marginal farmers and the least utilization of the land was performed by the medium farmers. Similarly, the land efficiency in terms of the productivity was also studied in the (Table 2). The (Table 2) shows that the efficiency of the land in terms of productivity was highest for marginal followed by small and medium farmers which is 138.31 per cent, 128.57 per cent and 121.63 per cent respectively.

So, marginal farmers have received highest productivity and the medium were with the lowest productivity. Therefore, we can say that proper use of each and every section of the land used in cultivation of sugarcane was efficient for the marginal farmers. Hence the farm efficiency in terms of land was maximum for the marginal farms and least for the medium farms (Fig. 1 and 2)

\section{Labor efficiency}

Profitability of any farm business is influenced by the efficiency of the labor resources employed. Hence, the details of the labor efficiency in terms of productive man work units for sugarcane crop was studied and presented in the (Table 3 and Fig. 3).

The (Table 3) infers that the PMWU was highest for medium farms 7523.71 and then 2462.87, 2323.83 for marginal and small farms. It shows that labors were efficiently used at the medium farms and the disposal of the labors at marginal and small farms were not efficiently used.

Similarly, the labor efficiency in terms of crop acreage per man is shown in (Table 4). Table 4 reveals that the crop acreage per man equivalent years was highest for medium farmers i.e. $57.88 \mathrm{ha} / \mathrm{yr}, 33.95 \mathrm{ha} / \mathrm{yr}$ for the small farmers and minimum for marginal farmers i.e. 3.25 ha/yr.

Therefore, it can be concluded that the medium farms of sugarcane crop is using labor resources inefficiently at the small and marginal farms and efficiently at the medium farms in the study area. 
Table.1 Village wise selected farmers under different size groups

\begin{tabular}{|c|c|c|c|c|c|c|c|c|c|}
\hline \multirow[t]{3}{*}{ S.No. } & \multirow[t]{3}{*}{ Village } & \multicolumn{6}{|c|}{ Size group of farms } & \multirow{2}{*}{\multicolumn{2}{|c|}{ Overall }} \\
\hline & & \multicolumn{2}{|c|}{ Marginal } & \multicolumn{2}{|c|}{ Small } & \multicolumn{2}{|c|}{ Medium } & & \\
\hline & & $\mathbf{P}$ & $\mathbf{S}$ & $\mathbf{P}$ & $\mathbf{S}$ & $\mathbf{P}$ & $\mathbf{S}$ & $\mathbf{P}$ & $\mathbf{S}$ \\
\hline 1 & Asrafpur & 65 & 9 & 30 & 3 & 58 & 6 & 153 & 18 \\
\hline 2 & Debri & 80 & 10 & 48 & 4 & 44 & 4 & 172 & 18 \\
\hline 3 & Malhepur & 89 & 11 & 45 & 5 & 60 & 6 & 171 & 22 \\
\hline 4 & Vishunpura & 72 & 10 & 28 & 3 & 52 & 5 & 116 & 18 \\
\hline 5 & Hakimpur & 91 & 11 & 69 & 7 & 65 & 6 & 161 & 24 \\
\hline & Total & 397 & 51 & 220 & 22 & 279 & 27 & 719 & 100 \\
\hline
\end{tabular}

Where, $\mathrm{P}=$ Population, S=Sample

Table.2 Per farm efficiency measures of sugarcane

\begin{tabular}{|c|c|c|c|}
\hline S.No. & Size of Farm & Production Efficiency (\%) & Cropping Intensity (\%) \\
\hline $\mathbf{1 .}$ & Marginal & 138.31 & 203.03 \\
\hline $\mathbf{2 .}$ & Small & 128.57 & 195.20 \\
\hline 3. & Medium & 121.63 & 181.78 \\
\hline
\end{tabular}

Table.3 PMWU of different size of farms

\begin{tabular}{|c|c|c|c|c|c|}
\hline S.No. & Size of farm & $\begin{array}{c}\text { Average man } \\
\text { days for } \\
\text { sugarcane per } \\
\text { ha }\end{array}$ & $\begin{array}{c}\text { Total area of } \\
\text { sugarcane(ha) }\end{array}$ & $\begin{array}{c}\text { Man equivalent } \\
\text { years }\end{array}$ & PMWU \\
\hline $\mathbf{1}$ & Marginal & 323 & 6.71 & & \\
\hline $\mathbf{2}$ & Small & 340 & 6.35 & 0.88 & $\mathbf{2 4 6 2 . 8 7}$ \\
\hline $\mathbf{3}$ & Medium & 356 & 20.50 & 0.94 & $\mathbf{2 3 2 3 . 8 3}$ \\
\hline
\end{tabular}

Table.4 Crop acreage per man (ha/yr)

\begin{tabular}{|c|c|c|c|c|}
\hline S.No. & Size of farms & $\begin{array}{c}\text { Total area } \\
\text { under crop }\end{array}$ & $\begin{array}{c}\text { Man equivalent } \\
\text { year }\end{array}$ & $\begin{array}{c}\text { Crop acreage per man } \\
\text { equivalent years }\end{array}$ \\
\hline 1. & Marginal & 6.71 & 0.88 & 3.25 \\
\hline 2. & Small & 6.35 & 0.94 & 33.95 \\
\hline 3. & Medium & 20.5 & 0.97 & 57.88 \\
\hline
\end{tabular}


Fig.1

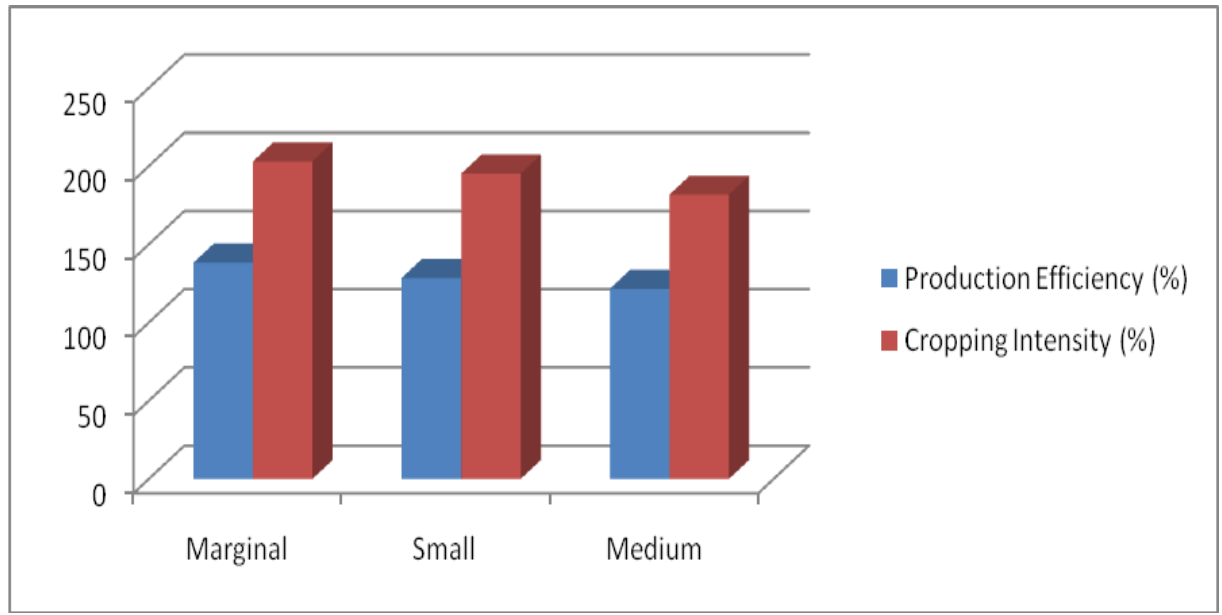

Fig.2

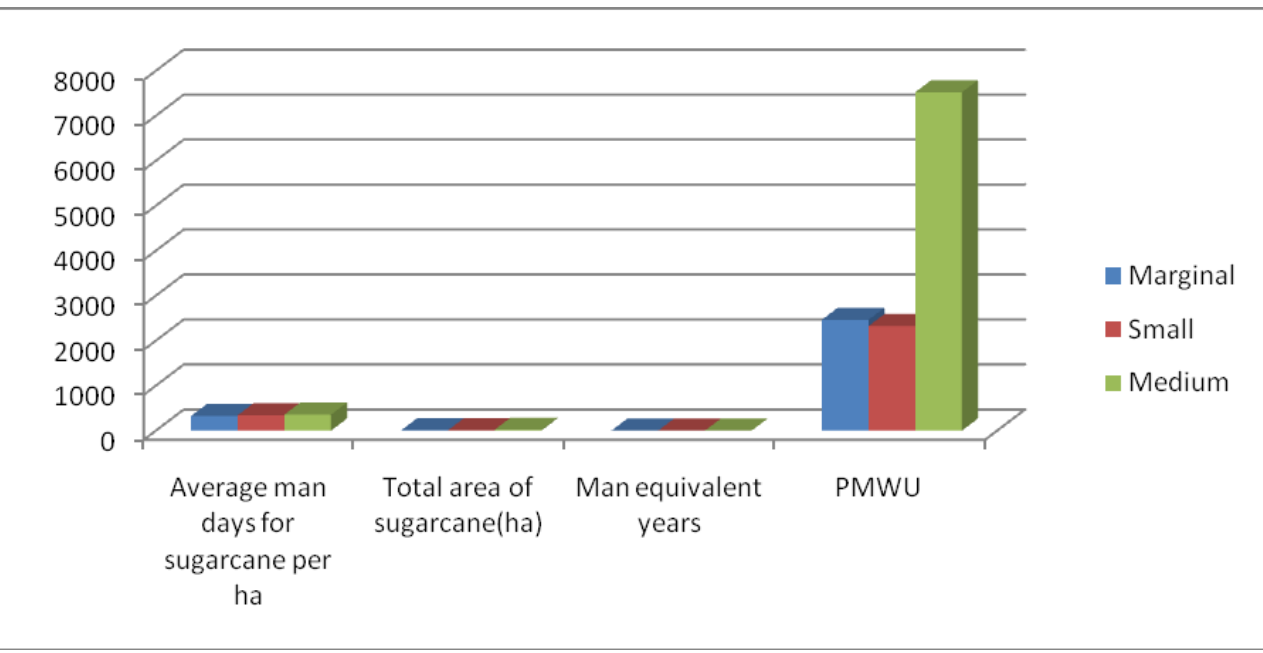

Fig.3

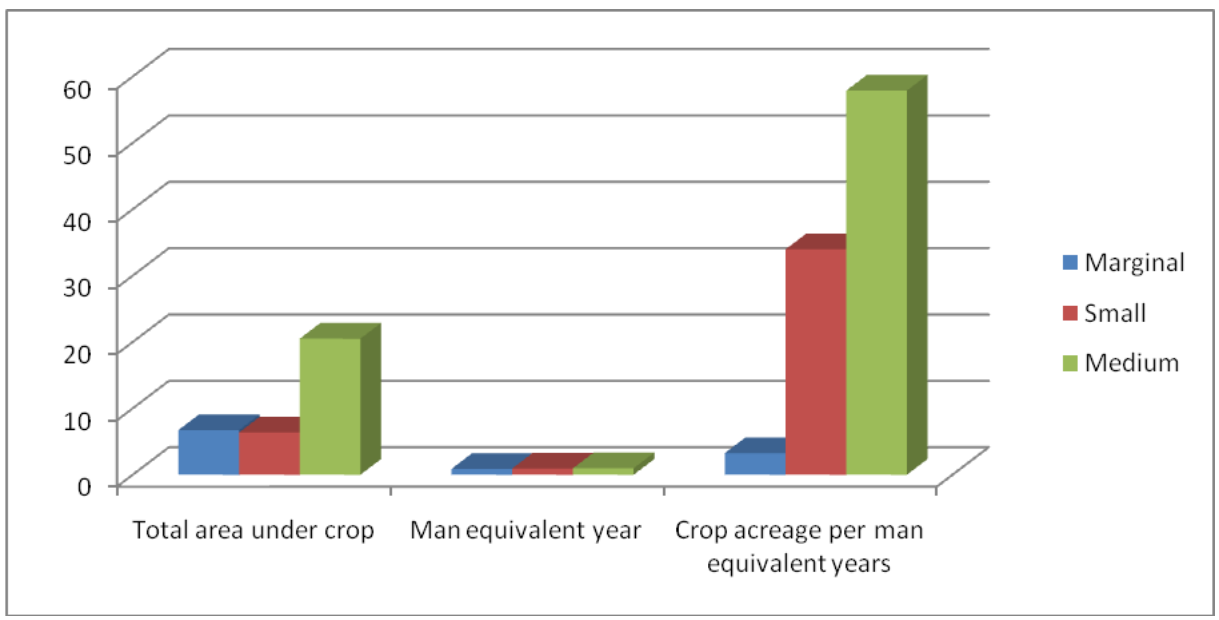


The work done on the farm by a worker in a day of eight hours is known as productive man work units.

\section{References}

Hussain Anwar and Neem-Ur-Rehman Khattak, (2011), Economic analysis of sugarcane crop in district Charsadda, Pakistan. Agricultural Research, 49(1):153.

Murali, P and Prathap, D. Puthira, (2016), technical efficiency of sugarcane farms: An econometric Analysis. Sugar Tech, 19(2).
Murthy, S.R.S., (2010), Economics of sugarcane production and processing(Report). Department of Economic Analysis and Research, NABARD, Mumbai, India.

Nagpure, S. C., Jhakare, A. B., Khandare, A. P. and Patil, R. K., (2004), Economics of Sugarcane production in Vidarbha Region of Maharashtra State. Rural India, 67 (6-7): 123-125.

Singh et al., 1994 Economic Analysis of sugarcane cultivation in Ramkola block, district Deoria (Uttar Pradesh), Bharatiya - Krishi - Anusandhan Patrika 1994, 9:1, 33-37, 4.

\section{How to cite this article:}

Bhartendu Yadav, Ram Singh Yadav, Vishakha Yadav, Pavan Kumar Singh and Ajeet Kumar. 2021. An Economic Analysis of Sugarcane Farm Efficiency. Int.J.Curr.Microbiol.App.Sci. 10(02): 1412-1417. doi: https://doi.org/10.20546/ijcmas.2021.1002.169 